\title{
Respiratory muscle pacing with chronically implanted intramuscular Permaloc electrodes: A feasibility study
}

\author{
James S. Walter, PhD; ${ }^{1-2 *}$ Robert D. Wurster, PhD; ${ }^{1,3}$ Qianlong Zhu, PhD; ${ }^{1}$ Franco Laghi, MD $^{\mathbf{4 - 5}}$ \\ ${ }^{1}$ Research Service, Edward Hines, Jr. Department of Veterans Affairs (VA) Hospital, Hines, IL; Departments of \\ ${ }^{2}$ Urology and ${ }^{3}$ Neurological Surgery and Physiology, Loyola University Medical Center, Maywood, IL; ${ }^{4}$ Section of \\ Pulmonary and Critical Care Medicine, Edward Hines, Jr. VA Hospital, Hines, IL; ${ }^{5}$ Division of Pulmonary and Critical \\ Care Medicine, Loyola University Medical Center, Maywood, IL
}

\begin{abstract}
We tested the feasibility of stimulating upperintercostal and abdominal muscles plus the diaphragm by using chronically implanted intramuscular electrodes. During two survival surgeries with six dogs, intramuscular electrodes were implanted bilaterally in the three respiratory muscles. Standard stimulation of the diaphragm was conducted. The dorsolateral and ventrolateral abdominal wall areas were stimulated with a $25 \mathrm{~mA}$ current. The second to fourth intercostal spaces were stimulated to elicit the largest tidal volume associated with the least coactivation of the serratus and latissimus muscles. Lone diaphragm and upper-intercostal muscle pacing produced inhaled tidal volumes (mean $+/$ - standard error of the mean) of $293+/-36 \mathrm{~mL}$ and $59+/-17 \mathrm{~mL}$, respectively. Lone abdominal muscle pacing produced an exhaled volume of $55+/-17 \mathrm{~mL}$. Combined pacing of diaphragm and intercostal muscles increased the inhaled volume to $389+/-39 \mathrm{~mL}$. The addition of abdominal pacing following the combined stimulation of diaphragm and intercostals increased the exhaled volume to $472+/-54 \mathrm{~mL}$. During autopsy, dislodgement of the electrodes overlying the ribs was a concern and probably resulted from loose animal jackets. Chronic intramuscular Permaloc electrodes can be implanted in several respiratory muscles and increase tidal volumes more than diaphragm stimulation alone.
\end{abstract}

Key words: animal model, electrical stimulation, feasibility study, functional electrical stimulation, intramuscular electrodes, muscle pacing, respiration, respiratory distress, spinal cord injury, tidal volume.

\section{INTRODUCTION}

The main muscles of inspiration are the diaphragm, external intercostal muscles, and accessory muscles of the shoulder and the upper back. The intercostal muscles assist the diaphragm by stabilizing and expanding the upper chest. Accessory muscles can also assist the diaphragm by lifting the upper thorax. Abdominal muscles are the primary muscles for cough and include the rectus and transversus abdominis and the internal and external obliques [1-2]. Patients with upper-cervical spinal cord injury (SCI) have paralysis of these respiratory muscles (although accessory respiratory muscles may still be active). Between 200 and 400 new SCI patients each year in the United States have this paralysis and the associated respiratory failure. Atelectasis and infection are the number one cause of death for these individuals [1-2].

\footnotetext{
Abbreviations: $\mathrm{ETCO}_{2}=$ end-tidal carbon dioxide, $\mathrm{SCI}=$ spinal cord injury, VA = Department of Veterans Affairs.

*Address all correspondence to James S. Walter, PhD; Edward Hines, Jr. VA Hospital, Research Service (151), Roosevelt and First Ave, Hines, IL 60141; 708-202-5805; fax: 708-202-2319. Email: James.Walter@va.gov DOI:10.1682/JRRD.2010.05.0086
} 
Most patients with upper-cervical SCI require ventilator support. Management is usually by positive pressure ventilation and, less often, by activation of the diaphragm muscle through phrenic nerve stimulation. Phrenic nerve stimulation is achieved with electrodes placed adjacent to the phrenic nerve. These electrodes are usually implanted in the mediastinum. More recently, diaphragmatic intramuscular electrodes provided with self-securing polypropylene anchors (Peterson, Synapse Biomedical, Inc; Oberlin, Ohio) have been used to deliver phrenic nerve stimulation [3-4].

Current methods of phrenic nerve and diaphragm stimulation have five potential limitations. The first limitation is insufficient ventilation during episodes of high demand, such as during respiratory pneumonia; thus, the ability to induce larger tidal volumes is needed [1]. The second limitation is diaphragm muscle atrophy, and this requires a period of training to restore muscle strength for individuals starting with phrenic pacing [4]. The third limitation is damage of the phrenic nerve motor neurons, which may preclude pacing. The fourth limitation is the inward rib cage movement that can accompany diaphragmatic contractions. This inward movement diminishes the efficiency with which diaphragmatic contractions generate tidal breathing; to overcome these limitations, researchers are studying the combined stimulation of upper-intercostal and diaphragm muscles [5-9]. The goal of intercostal stimulation is stabilization and expansion of the thorax during diaphragm stimulation. The fifth limitation of phrenic nerve pacing is a lack of activation of abdominal muscles. Ventilation achieved with combined stimulation of intercostals and diaphragm muscles can be further augmented with stimulation of the abdominal expiratory muscles during exhalation [5,9]. Expiration is normally passive, being produced by passive recoil of the stretched lung-spring. Expiratory muscle stimulation during exhalation enlarges the exhaled volume, which in turn allows the stretched chest wall-spring to contribute to the volume of inhalation following the end of abdominal stimulation. In addition, abdominal muscle stimulation can be used for cough and removal of respiratory secretions [1]. A high stimulation current that induces strong abdominal muscle contractions is needed to produce high flow rates and large expired volumes for cough [1].

In patients [10-18] and laboratory animals [5-7,19], stimulation of extradiaphragmatic respiratory muscles has been achieved with the use of ventral epidural elec- trodes, electrodes implanted at the spinal foramina close to the ventral roots, and surface electrodes (expiratory muscles). The feasibility of pacing upper-intercostal and abdominal muscles plus the diaphragm with chronically implanted intramuscular electrodes (Permaloc, Synapse Biomedical, Inc) ${ }^{*}$ remains uncertain. Accordingly, the current investigation assessed the response to respiratory muscle stimulation through these intramuscular electrodes chronically implanted in the diaphragm, upperintercostal, and abdominal muscles. Each muscle group was stimulated alone or with the others 2 to 4 months after placement of the intramuscular electrodes [20]. In addition, the status of the electrodes at autopsy is reported.

\section{METHODS}

The study was conducted in two male and four female short-hair, adult dogs weighing from 20 to $27 \mathrm{~kg}$. These same animals were studied in an earlier acute investigation whose main aim was to develop a surgical technique to implant intramuscular electrodes provided with self-securing polypropylene anchors in the upper intercostals and abdominal-wall muscles [20].

\section{Placement of Electrodes}

Permaloc electrodes were implanted with a 16-gauge needle (Synapse Biomedical, Inc) in the diaphragm, abdominal, and upper-thorax intercostal muscles (two bilateral pairs in each muscle group) [20]. In the diaphragm, one pair of electrodes was implanted lateral to the inferior vena cava and central tendon and the second pair of electrodes was implanted $2 \mathrm{~cm}$ dorsal to the first. Abdominal electrodes were implanted in dorsolateral areas and in ventrolateral areas that were a few centimeters caudal to the 13th rib. Upper-intercostal electrodes were implanted in a lateral area of the second and fourth or third and fourth intercostal spaces. Leads from the intramuscular electrodes traversed the skin in the upper torso caudal to the shoulders. They were placed in a connector (Synapse Biomedical, Inc) and kept in a pocket of the animal's jacket (Alice King Chatham Medical Arts;

\footnotetext{
*The Permaloc electrodes are identical to the Peterson electrodes (Synapse Biomedical, Inc) already in use for diaphragm stimulation in the SCI patient with respiratory apnea.
} 
Hawthorne, California) [20]. Twenty-two gauge wire was tied to all jacket zippers to prevent them from opening or the animal from getting the jacket off. A neck collar was also used to limit the animal chewing on the jackets and leads. (For further details on the surgical techniques, see Walter et al. [20].)

\section{Pacing of Respiratory Muscles}

The efficacy of respiratory muscle pacing with chronically implanted intramuscular electrodes was tested over a 2- to 4-month period after the last surgery [20]. Electrical stimulation was given while the test animals were under general anesthesia, this being done up to six times at triweekly intervals. Anesthesia was initiated with intravenous Propofol (6 mg/kg bolus) followed by Isoflurane (2\%-3\%) delivered through an endotracheal tube. Preoperative atropine $(0.05 \mathrm{mg} / \mathrm{kg}, \mathrm{IV})$ was administered to reduce secretions. Body temperature was maintained between $100{ }^{\circ} \mathrm{F}$ and $103{ }^{\circ} \mathrm{F}$ with a heating pad. During anesthesia, the animals were artificially ventilated (Draeger Anesthesia Ventilator, Draeger Medical Inc; Telford, Pennsylvania). Ventilation was titrated between 250 and $350 \mathrm{~mL}$ to maintain a partial pressure of endtidal carbon dioxide $\left(\mathrm{ETCO}_{2}\right)$ at $35 \mathrm{mmHg}$, which was digitally displayed (Tidal Wave Capnograph/Oximeter, DRE Veterinary; Louisville, Kentucky).

Airflow was monitored with a pneumotachometer (A. Fleish, OEM Medical; Richmond, Virginia) that had been calibrated with a ball meter (\#13, Cole-Parmer; Vernon Hills, Illinois). The flow signal was integrated (Gould Integrator unit, Gould; Valley View, Ohio) to obtain the tidal volume. Esophageal pressure was monitored with use of a balloon-tipped catheter just rostral to the diaphragm. Respiratory pneumobelts were placed on the midthorax and midabdomen to record movements of the thoracic and abdominal compartments. All pressures were recorded with Statham pressure transducers (P23AC, Statham Inc; Hato Rey, Puerto Rico) and amplified by Gould preamplifiers. Recordings were displayed on an 8-channel recorder (Astromed Inc; West Warwick, Rhode Island).

Respiratory pacing was studied with use of electrical stimulations delivered with a 12-channel stimulator (Permaloc Stimulator System, Synapse Biomedical, Inc). Stimulations consisted of constant-current, balanced, monophasic pulses. The stimulator allowed the operator to control the frequency of stimulation (in hertz), pulse duration, current amplitude (maximum current of $25 \mathrm{~mA}$ ), respiration rate, and combination of muscles stimulated.

\section{Pacing of Individual Respiratory Muscles}

Pacing was conducted during hyperventilation-induced apnea. Hyperventilation was achieved by increasing the ventilator rate to approximately 24 respirations/min until the $\mathrm{ETCO}_{2}$ decreased to 20 to $25 \mathrm{mmHg}$. Testing during the 2 to 3 min periods of respiratory apnea was conducted with respiratory pacing at 14 respirations/min. Stimulations delivered within $15 \mathrm{~s}$ of a spontaneous inspiratory effort were excluded from analysis.

The standard parameters of stimulation in each area to be used during pacing were determined by conduction of current-response testing first with single, then with bilateral, and finally with the two bilateral pairs of electrodes. The standard parameters for diaphragm stimulation were $20 \mathrm{~Hz}, 50 \mu$ s duration-pulses, inspiration time of $1.2 \mathrm{~s}$, and 20 respirations/min. Further, the standard current produced an $\mathrm{ETCO}_{2}$ of $35 \mathrm{mmHg}$. The standard parameters for the abdominal muscle stimulation included the four implanted electrodes and $25 \mathrm{~mA}, 20 \mathrm{~Hz}, 100 \mu \mathrm{s}$ duration-pulses and an expiration time of $1 \mathrm{~s}$. Deviations from this standard for individual animals is detailed below. Frequency-response testing (10, 20 to $50 \mathrm{~Hz}$ ) was also conducted in these muscles.

Standard parameters of stimulation for the upperintercostal muscles were $20 \mathrm{~Hz}, 100 \mu \mathrm{s}$, and $1.2 \mathrm{~s}$ inspiration time. The intensity of stimulation was titrated in order to achieve the greatest chest expansion while causing the least stimulation of unwanted muscles overlying the ribs: serratus and latissimus (contraction of these muscles did not appear to contribute to chest expansion [20]). However, chest expansion during intercostal muscle stimulation was not observed without unwanted contraction of these muscles, and Permaloc electrodes were not used as part of the standard stimulation conditions if they caused contraction of these unwanted muscles before they contributed to the inhaled tidal volume.

\section{Pacing of Combined Respiratory Muscles}

The purpose of the combined respiratory muscle pacing was to assess whether adding intercostal and/or abdominal muscles would augment the tidal volumes elicited by diaphragmatic pacing alone. Intercostal muscle pacing was conducted synchronously with the diaphragm and was immediately followed by abdominal muscle pacing. 


\section{Animal Care, Autopsy, and Statistics}

Surgical and postsurgical care was conducted as previously described [7]. Animals were housed in large cages with rubber objects for chewing, were fed regularly, and received veterinarian inspections. While under deep anesthesia induced with 3 percent Isoflurane, animals were sacrificed by administration of $50 \mathrm{~mL}$ of saturated $\mathrm{KCl}$ intravenously. During autopsy, the location of the intramuscular electrodes in the three respiratory muscles was determined by dissection and photographed.

Summary results are presented as mean \pm standard error of the mean. Student $t$-tests for paired data were conducted for all statistical analyses.

\section{RESULTS}

\section{Animal Care}

In all animals, one of the three zippers on the jackets opened at least once. This loosened the jacket, causing tension on the electrode leads and, sometimes, dislodgement of the intramuscular electrodes. Collars designed to make it difficult for the dog to gnaw on its jacket were utilized to minimize this problem. No skin infections were observed where the electrodes exited the skin. Autopsy results are described for the electrodes in each of the three respiratory muscles.

\section{Stimulation of Diaphragm Muscle}

A single pair of Permaloc electrodes in the diaphragm produced sufficient tidal volume for these studies. The pair lateral to the inferior vena cava - the closest to the phrenic nerve- - was used in three of the animals. In two animals, the pair of electrodes located $2 \mathrm{~cm}$ dorsal to the inferior vena cava was used because it produced a more graded inhalation during electrical stimulation. In the sixth animal, stimulation was only conducted with one electrode in the right hemidiaphragm because both electrodes in the left side failed to work and it was determined later at autopsy that the left electrodes had dislodged for reasons mentioned earlier. Importantly, the respiratory recordings from this animal appeared similar to the recordings from other animals and were included in the results.

As the current applied to the diaphragm was increased from 5 to $25 \mathrm{~mA}$, tidal volume increased to a maximum of $435 \pm 57 \mathrm{~mL}$ (Table 1). The standard stimulating current $\left(\mathrm{ETCO}_{2}\right.$ of $\left.35 \mathrm{mmHg}\right)$ determined at
Table 1.

Effects of current amplitude on tidal volume in response to stimulation of diaphragm. Three animals were stimulated with bilateral Permaloc electrodes lateral to vena cava: two were stimulated with bilateral pair $2 \mathrm{~cm}$ dorsal for vena cava and one was paced with single electrode on right hemidiaphragm. Other standard stimulating parameters included $20 \mathrm{~Hz}, 50$ or $20 \mu$ s pulse duration, and $1.2 \mathrm{~s}$ inspiration period. $n=6$.

\begin{tabular}{cc}
\hline Current $(\mathbf{m A})$ & Tidal Volume $(\mathbf{m L})$ \\
\hline 5 & $91 \pm 16$ \\
10 & $251 \pm 40$ \\
15 & $335 \pm 63$ \\
25 & $435 \pm 57$ \\
\hline \hline
\end{tabular}

14 respirations/min was $12 \pm 1 \mathrm{~mA}$ and produced a tidal volume of $315 \pm 19 \mathrm{~mL}$.

\section{Stimulation of Abdominal Muscles}

Although contraction of the abdominal-wall muscles could be palpated close to the intramuscular electrode, stimulation through any single Permaloc electrode produced no exhaled volume at stimulating currents up to $25 \mathrm{~mA}$. Similarly, bilateral stimulation of the ventrolateral and dorsolateral abdominal-wall areas with stimulating currents up to $25 \mathrm{~mA}$ and frequency set at $10 \mathrm{~Hz}$ caused muscle vibration but produced little or no exhaled volume. In contrast, bilateral stimulations with stimulating currents up to $25 \mathrm{~mA}$ and stimulating frequencies set at 20 or $50 \mathrm{~Hz}$ elicited exhaled volume (and upward pulling of the pubic bone). Although stimulation frequency set at $50 \mathrm{~Hz}$ produced larger exhaled volumes than $20 \mathrm{~Hz}$ (Table 2), pacing was conducted at $20 \mathrm{~Hz}$ in three of the animals because $50 \mathrm{~Hz}$ is considered a fatigue-inducing frequency for long-term pacing $[3,8]$. However, in the two remaining animals, a stimulation frequency of $50 \mathrm{~Hz}$ during pacing was chosen because it ensured the generation of more than $20 \mathrm{~mL}$ of exhaled volume. In all animals, as the stimulating current was increased, exhaled volumes recorded with bilateral stimulation progressively increased as well (Figure 1).

Exhaled volumes recorded when the stimulating current $(25 \mathrm{~mA}$ and $20-50 \mathrm{~Hz}$ ) was delivered through the dorsolateral electrodes or through combined dorsolateral plus ventrolateral electrodes were larger than when ventrolateral electrodes alone were used (Table 2). In one animal, abdominal muscle stimulation produced inspiration and was excluded from further testing. At autopsy, 20 of the 24 abdominal-wall electrodes were found to be located within the areas where the electrodes had been 
Table 2.

Exhaled volumes elicited by stimulation of different abdominal muscles during current-response testing. Also, effects of stimulating frequency on exhaled volumes elicited by stimulation of electrodes located in dorsolateral and ventrolateral areas.

\begin{tabular}{|c|c|c|c|c|}
\hline \multirow{2}{*}{ Stimulated Electrode } & \multicolumn{4}{|c|}{ Current Amplitude (mA) } \\
\hline & 5 & 10 & 15 & 25 \\
\hline \multicolumn{5}{|l|}{ 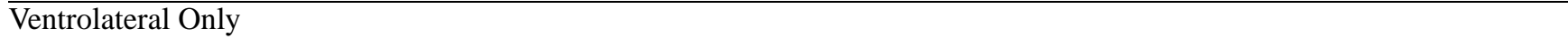 } \\
\hline Tidal Volume (mL) & $4 \pm 4$ & $4 \pm 4$ & $4 \pm 4$ & $8 \pm 5$ \\
\hline \multicolumn{5}{|l|}{ Dorsolateral Only } \\
\hline Tidal Volume (mL) & $5 \pm 3$ & $16 \pm 4$ & $25 \pm 7$ & $30 \pm 10^{\dagger}$ \\
\hline \multicolumn{5}{|l|}{ Dorsolateral + Ventrolateral } \\
\hline \multirow[t]{3}{*}{ Tidal Volume (mL) } & $15 \pm 5$ & $22 \pm 6$ & $26 \pm 14$ & $54 \pm 10^{\dagger}$ \\
\hline & \multicolumn{4}{|c|}{ Stimulation Frequency $(\mathrm{Hz})^{\ddagger}$} \\
\hline & 10 & & & 50 \\
\hline \multicolumn{5}{|l|}{ Dorsolateral + Ventrolateral } \\
\hline Tidal Volume (mL) & $8 \pm 8$ & & & $53 \pm 9^{\ddagger}$ \\
\hline
\end{tabular}

implanted during surgery (Figure 1). In the remaining four dogs, 4 electrodes could not be located. These findings suggest that these electrodes had become dislodged from their original position, possibly because of tension on the electrode leads. We cannot exclude the possibility that one or more of the dislodged "abdominal-wall electrodes" might have activated the diaphragm. As expected, dislodged electrodes did not contribute to expired volumes during abdominal muscle stimulation.

\section{Stimulation of Upper-Thorax Muscles}

In one animal, the four electrodes implanted in the intercostal muscles were inadvertently pulled just under the skin into the ventral portion of the thorax. Consequently, when currents were delivered through these electrodes, only unwanted latissimus and serratus muscle contractions occurred and no tidal volume resulted. Therefore, no upper-thorax muscle pacing was conducted in this animal. In the remaining five animals, additional precautions were taken to prevent electrode dislodgement (see "Animal Care" section). The average inhaled volume elicited with the upper-thorax electrodes was $67 \pm$ $10 \mathrm{~mL}$ with standard stimulation current for individual animals set between 5 and $25 \mathrm{~mA}$. Of interest, at autopsy 15 of the 20 upper-intercostal electrodes in these five animals had also become dislodged and rested in or over the serratus or latissimus muscles overlying the ribs (Figure 2).

\section{Pacing of Respiratory Muscles with Intramuscular Electrodes}

Representative respiratory pacing records for one animal using standard stimulation conditions are shown in Figure 3. Diaphragm stimulation produced a tidal volume of $260 \mathrm{~mL}$ and a maximal negative esophageal pressure of $-5 \mathrm{~cm} \mathrm{H}_{2} \mathrm{O}$. Diaphragm contraction was accompanied by inward movement of the upper thorax (Figure 3: short dashed arrows). This inward movement was observed in all six animals [1,3]. (In contrast, spontaneous inspirations in these animals always produced upper-thorax expansion [data not shown].)

In the representative animal (Figure 3), solitary abdominal muscle stimulation elicited an exhaled volume of $75 \mathrm{~mL}$. This additional exhaled volume contributed to the subsequent inhaled volume when applied alone, following diaphragm alone and combined diaphragm and upper-intercostal stimulation (Figure 3: solid black arrows). In all animals, when the abdominal-wall muscles were relaxed, the ventral portion of the abdomen had a concave shape. The contraction of the abdominal-wall muscles elicited by electrical stimulation caused a tension of the abdominal-wall muscles. This tension translated into a "straightening" of the ventral portion of the abdomen. The straightening was recorded as a "paradoxical" expansion of the abdominal compartment (Figure 3: arrow heads). 


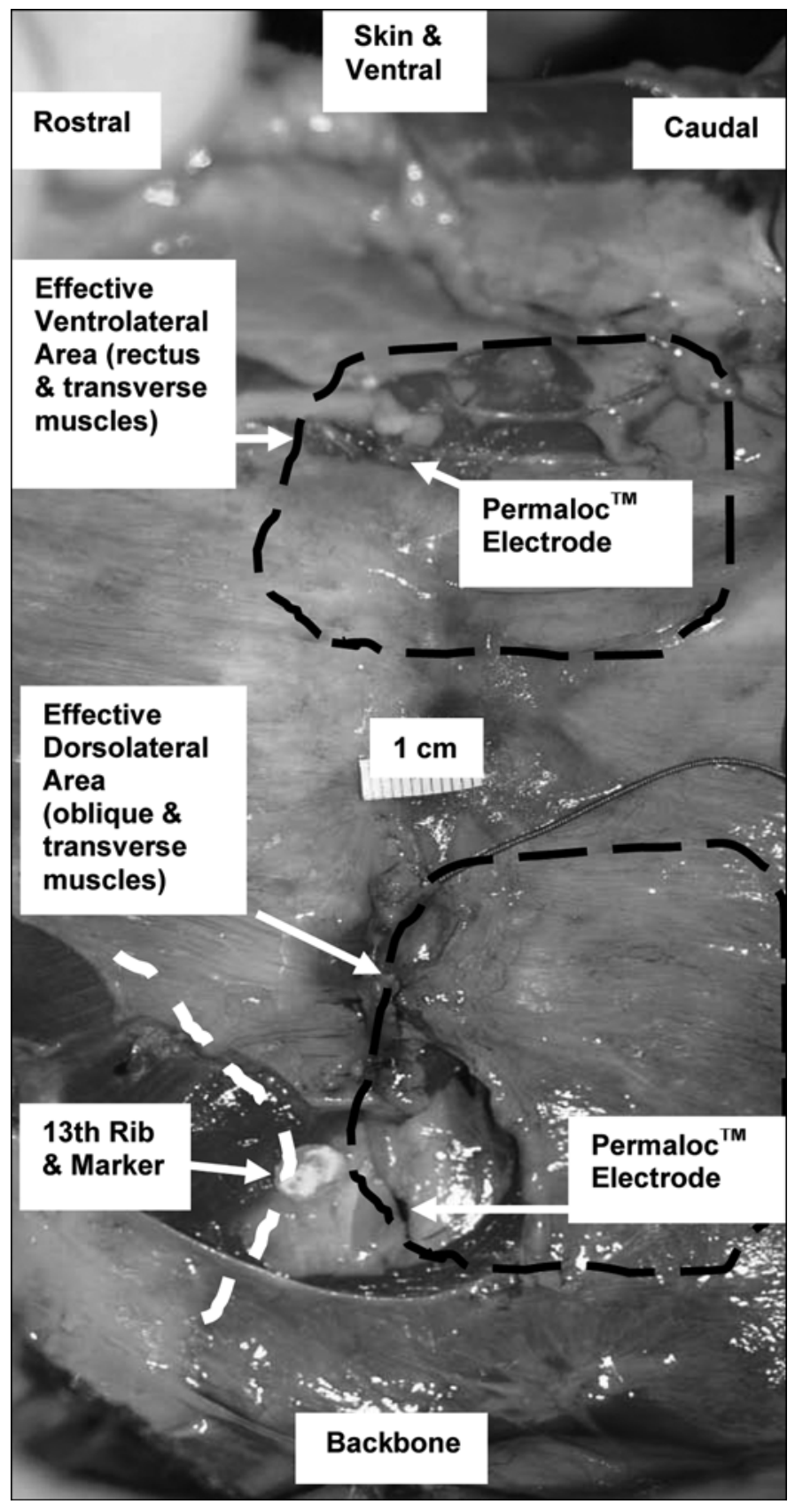

Figure 1.

Peritoneal section and midsection of left abdominal wall in representative animal during autopsy. Two dissected Permaloc electrodes are shown in area circumscribed by dashed black lines that indicate areas tested for implantation of electrodes. Polypropylene anchors of electrodes are shown at arrows. Ventrolateral electrode was about $5 \mathrm{~mm}$ deep in muscle whereas dorsolateral electrode was about $1 \mathrm{~cm}$ deep. These electrodes were secure where they had been implanted. White disk placed over muscle marks 13th rib below it. Electrodes were implanted for 54 days.

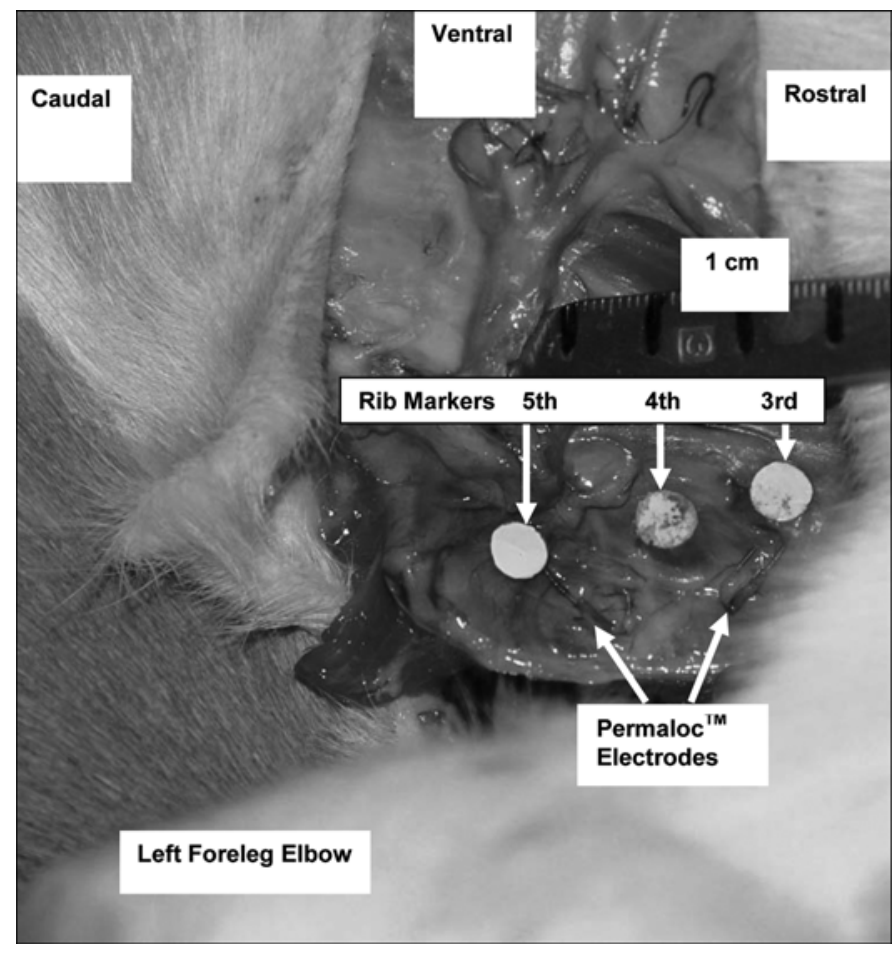

Figure 2.

Superficial muscles of lateral upper-thorax area during autopsy. Polypropylene anchors of two dissected Permaloc electrodes are shown at arrows. They are located at third and fourth intercostal spaces. Their location overlying serratus and latissimus muscles shows that the electrodes became dislodged from underlying intercostal muscles where they had been implanted. Electrodes were implanted for 40 days.

The effects of stimulation of the upper-intercostal muscles are also shown in Figure $\mathbf{3}$ under the heading of thorax at the base of the figure. Two of the implanted electrodes in this area were not paced because initial testing demonstrated that they produced more than slight/ moderate contraction of latissimus and serratus muscles before generating an inhaled tidal volume. Thus, only the remaining two bilateral thorax electrodes were used (see Figure 3). Stimulating currents applied to the two effective electrodes were $5 \mathrm{~mA}$ (right third thoracic intercostal space) and $25 \mathrm{~mA}$ (left fourth thoracic intercostal space). Stimulation through these electrodes produced a tidal volume of $100 \mathrm{~mL}$ and expansion of the thorax with not more than slight/moderate contraction of latissimus and serratus muscles (Figure 3: long dashed arrows). Thoracic expansion during upper-intercostal stimulation was recorded in all six animals.

Combined muscle stimulation is shown in the right columns of Figure 3. Stimulating the abdominal muscle 


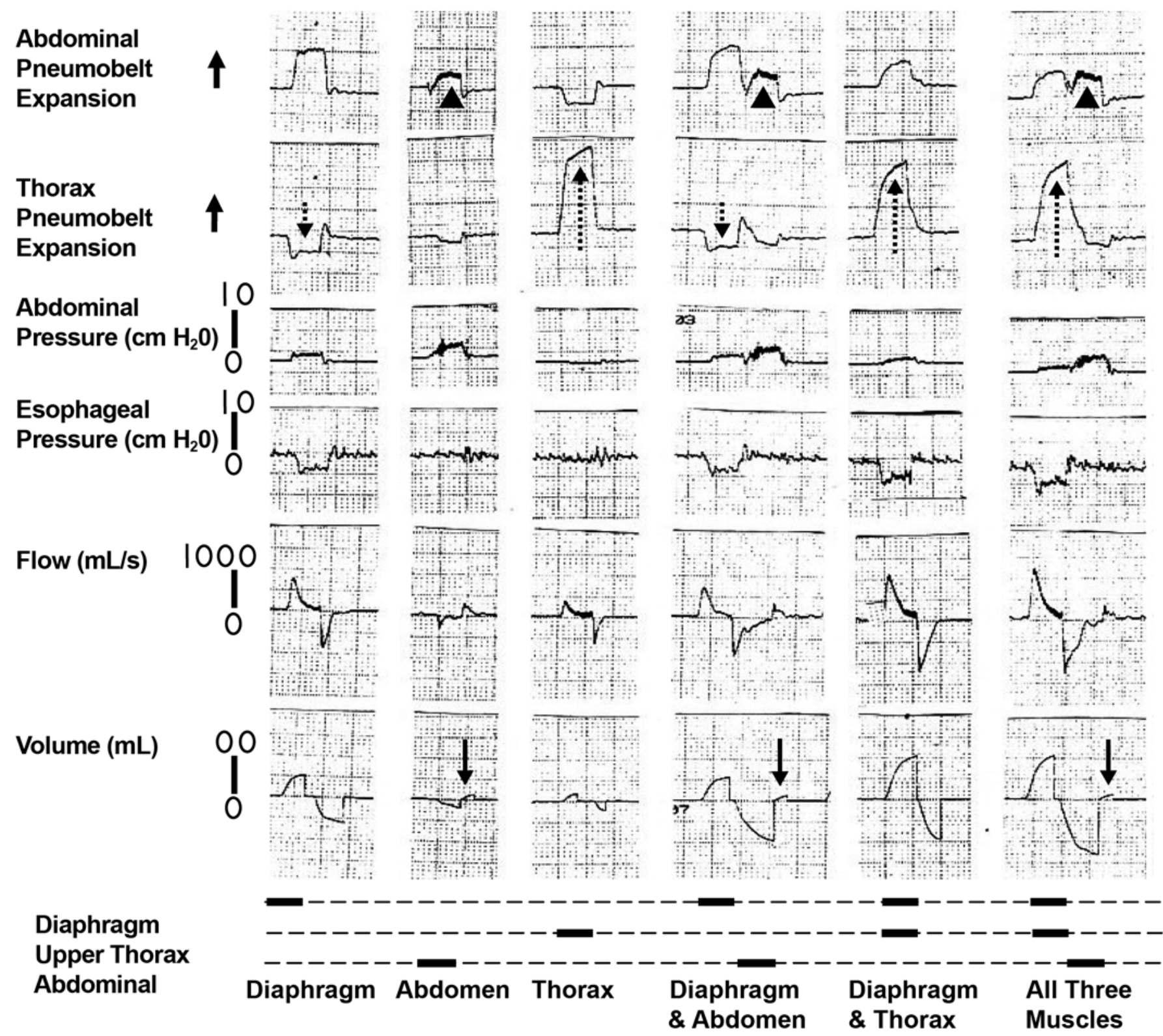

Figure 3.

Tracings of air flow, tidal volume, and other respiratory measures in representative dog during standard stimulation of diaphragm (12 mA), abdominal (maximum $25 \mathrm{~mA}$ ), and thorax (upper-intercostals, 5-25 mA) muscles alone and then in combination. Stimulations were delivered at $20 \mathrm{~Hz}$ and 50 or $100 \mu$ s pulses and with stimulation periods of 1.0 or $1.2 \mathrm{~s}$. Stimulation of diaphragm at $12 \mathrm{~mA}$ was used because it produced end title volume of $35 \mathrm{mmHg}$. Abdominal pneumobelt recordings show paradoxical expansion of abdomen during abdominal muscle stimulation (arrow head). Thorax pneumobelt recordings show decreased expansion of upper chest during diaphragm stimulation (short dashed arrows). These same recordings show expansion of upper chest during thorax (upper-intercostals) stimulation alone or combined with diaphragm (long dashed arrows). Airway volume records show rebound tidal volume following expiration with abdominal stimulation (solid arrows). Recording during third anesthesia and testing period.

immediately after previously stimulating the diaphragm increased exhaled volume from 300 to $470 \mathrm{~mL}$. Combined stimulation of the inspiratory thoracic muscles and the diaphragm followed by abdominal-wall stimulation further increased the exhaled volume to $650 \mathrm{~mL}$. Stimulation of the thoracic muscles combined with stimulation 
of the diaphragm increased inhaled volume and prevented the inward movement of the ribs that occurred during stimulation of the diaphragm alone (Figure 3: long dashed arrows).

The results of individual and combined muscle pacing are summarized in Table 3 . Solitary stimulation of the diaphragm produced greater inhaled and exhaled volumes and flows than solitary stimulation of thoracic inspiratory muscles or solitary stimulation of abdominal (expiratory) muscles. As compared with solitary stimulation of the diaphragm, combined stimulation of the diaphragm and upper-thorax respiratory muscles increased inhaled volumes and caused a nonsignificant increase in exhaled volumes and inspiratory and expiratory flows. Despite a trend for greater abdominal pressures, flows, and exhaled volumes recorded in response to sequential stimulation of the diaphragm and abdominal muscles, these values were not statistically different from the corresponding values recorded with solitary stimulation of the diaphragm. The largest inspiratory and expiratory flows and volumes were recorded when the diaphragm and thoracic muscles were stimulated simultaneously, followed by stimulation of the abdominal muscles.

\section{DISCUSSION}

This feasibility study testing Permaloc intramuscular electrodes has two novel findings. First, stimulating extradiaphragmatic muscles with the electrodes is possible. Second, combined stimulation of the diaphragm and upper-intercostal muscles during inhalation followed by abdominal-wall muscle stimulation during exhalation augments tidal volumes as compared with stimulation of the diaphragm alone. However, greater respiratory responses to stimulation of extradiaphragmatic muscles are needed to warrant clinical application.

The tidal volumes achieved $(>250 \mathrm{~mL})$ by stimulation of the diaphragm only (Table 1 and Figure 1) are probably greater than those of a nonexercising, nonanesthetized $25 \mathrm{~kg}$ dog but are similar to previously reported volumes with diaphragm stimulation with this type of electrode in anesthetized dog models [5-6]. In addition, tidal volumes of similar magnitudes (milliliters of tidal volume per kilogram of body weight) can be achieved in humans with Peterson electrodes (analogous to Permaloc) implanted so as to only stimulate the diaphragm. Thus, also stimulating external intercostal muscles or abdominal muscles is not necessary to maintain adequate alveolar ventilation in a nonexercising, paralyzed individual [4]. On the other hand, when a human needs to cough, larger inspiratory and expiratory volumes are required, whereupon stimulation of accessory inspiratory and expiratory muscles will be necessary. Even then, an effective cough can only be achieved if, during an electrically induced forced expiration, the glottis can be partially closed. Accomplishing this at just the right moment will be another technical achievement. Larger tidal volumes will also be necessary if an occasional "sigh" is important (and it probably is) in a human subject whose respiration is supported with implanted electrodes.

Table 3.

Respiratory volumes, flow rates, and esophageal and abdominal pressure (Pr) with stimulation of respiratory muscle groups alone and then together in various combinations.

\begin{tabular}{|c|c|c|c|c|c|c|}
\hline \multirow{2}{*}{ Muscle } & \multicolumn{2}{|c|}{ Volume (mL) } & \multicolumn{2}{|c|}{ Flow $(\mathrm{mL} / \mathrm{s})$} & \multirow{2}{*}{ 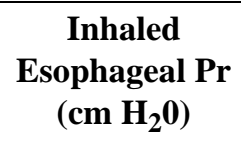 } & \multirow{2}{*}{$\begin{array}{l}\text { Exhaled } \\
\text { Abdominal Pr } \\
\quad\left(\mathrm{cm} \mathrm{H}_{\mathbf{2}} \mathbf{0}\right)\end{array}$} \\
\hline & Inhaled & Exhaled & Inhaled & Exhaled & & \\
\hline Diaphragm & $293 \pm 36$ & $299 \pm 32$ & $672 \pm 105$ & $873 \pm 71$ & $-3 \pm 1$ & $0 \pm 0$ \\
\hline Thorax & $59 \pm 17$ & - & $184 \pm 56$ & $312 \pm 84$ & $-1 \pm 1$ & $0 \pm 0$ \\
\hline Abdomen & - & $55 \pm 17$ & - & $135 \pm 38$ & - & $4 \pm 1$ \\
\hline Diaphragm + Abdomen & $319 \pm 42$ & $379 \pm 43$ & $599 \pm 121$ & $838 \pm 79$ & $-3 \pm 1$ & $4 \pm 1$ \\
\hline Diaphragm + Thorax & $389 \pm 39^{\dagger}$ & $382 \pm 30$ & $805 \pm 144$ & $1,000 \pm 62$ & $-3 \pm 1$ & $2 \pm 1$ \\
\hline All Three Muscles & $409 \pm 47^{\ddagger}$ & $472 \pm 54^{\ddagger}$ & $850 \pm 130^{\ddagger}$ & $1,000 \pm 83^{\ddagger}$ & $-4 \pm 1$ & $4 \pm 1^{\ddagger}$ \\
\hline
\end{tabular}

${ }^{*}$ Testing at 14 respirations/min using standard stimulation conditions; $n=5$ for all tests.

${ }^{\dagger}$ Significant difference between diaphragm stimulation alone and simultaneous diaphragm and upper-thorax intercostals muscle stimulation $(p=0.05)$.

${ }^{\ddagger}$ Significant differences between stimulation of diaphragm vs the designated combination of muscle groups: inhaled tidal volume $(p=0.05)$, exhaled tidal volume ( $p=$ $0.03)$, inhaled flow rate $(p=0.02)$, exhaled flow rate $(p=0.003)$, and exhaled abdominal pressure $(p=0.04)$. 


\section{Respiratory Pacing with Intramuscular Electrodes}

\section{Diaphragm Stimulation}

As just noted, diaphragm stimulation alone could induce adequate tidal volumes in this animal model. However, diaphragm stimulation also resulted in an inward movement of the rib cage. This movement is similar to the problem reported for SCI patients using diaphragm stimulation [3-4]. The inward movement diminishes the extent to which diaphragmatic contraction lowers intrapleural pressure and, thus, decreases the volume of inspired air. Contraction of the external intercostal muscles pulls the ribs outward, thereby preventing the inward movement of the upper rib cage; the net effect is to augment the volume of inspired air (Figure 3).

\section{Abdominal Muscle Stimulation}

Increasing the exhaled volume by stimulation of abdominal (expiratory) muscles contributes to the tidal volume. This occurs because muscle-enhanced expiration forces the rib-spring inward to a point at which the ribspring recoils outward after the end of abdominal stimulation. In doing so, the rib-spring augments the inhaled volume. However, the observed exhaled volumes are small: less than $100 \mathrm{~mL}$. These volumes are not larger than our previous report with abdominal stimulation using four model microstimulators [9].

In an anesthetized dog model, DiMarco et al. reported strong abdominal muscle contraction with an average exhaled volume of $218 \mathrm{~mL}$ produced with epidural electrodes on the dorsal side of the spinal cord in the lower thoracic area [5]. In addition, clinical studies with abdominal surface electrodes and electrodes on the lower ventral side of the spinal cord have produced exhaled volumes greater than $1 \mathrm{~L}[10-15,18]$. These large exhaled volumes provide a standard for comparison of alternative techniques. DiMarco et al. attributed their large exhaled volumes during ventral spinal cord stimulation to the spread of the electric field to stimulate the abdominal innervation at several spinal levels [5-6,18]. Lin et al. also reported that stimulation of more levels with more electrodes is important [19]. Several mechanisms probably contributed to our smaller expired volumes. Our stimulation was limited to two bilateral abdominal sites and a maximal stimulation current of $25 \mathrm{~mA}$. In addition, current stimulation in the middle of abdominal muscles may have been a limitation, because sites closer to the spinal origin may produce greater abdominal contractions [19].

\section{Upper-Thorax Intercostal Muscle Stimulation}

Functional stimulation of the upper-intercostal muscles elicited only small tidal volumes. These contrast with the results of DiMarco et al. [5-6]. These investigators attributed the large volume responses to spread of the electric field to several thoracic levels from their sites of epidural stimulation along the ventral side of the spinal cord. Several mechanisms probably contributed to our results. We stimulated only two intercostal muscles from each hemithorax, while DiMarco et al. probably stimulated the second through the fifth intercostal muscles by using the more invasive techniques of stimulation of the ventral aspect of the spinal cord [5-6].

Unwanted contraction of latissimus and serratus muscles overlying the ribs was a limiting factor. This limitation was generally identified during autopsy to be caused by dislodgement of the intramuscular electrodes from their implantation site in the intercostal muscles as they had migrated to the latissimus and serratus muscles (Figure 2).

In addition, intercostal muscles include both the external and internal muscles. The larger external intercostal muscles assist in inspiration when the tidal volume is large by pulling the ribs upward and outward. They also firm up the space between the ribs, preventing the space between the ribs from moving inward during deep diaphragmatic breathing. The internal intercostal muscles assist in forced expiration by pulling the ribs downward and inward. We suspect that that the current "thoracicmuscle stimulation" was largely stimulation of external intercostal muscles because only inspirations were recorded.

\section{Limits of Techniques}

A limitation of these studies was dislodgement of the intramuscular electrodes over the 2 to 3 months of instrumentation, most likely due to tension on the electrode leads when the jackets became loose. This was most severe for the thoracic electrodes, because they were inserted close to the point at which the wires exited the skin and, thus, were more susceptible to displacement.

\section{Future Directions}

This feasibility study supports the possibility of using Permaloc electrodes chronically implanted in extradiaphragmatic respiratory muscles and could have a role in respiratory management. The analogous Peterson electrode is already being used widely for respiratory management with diaphragm stimulation in patients with upper-cervicallevel SCI [3-4]. As detailed in the "Introduction," five 
areas exist in which extradiaphragmatic muscle stimulation may help address possible limitations of diaphragm stimulation alone. In the current studies, there were limitations to the intramuscular electrode in the upper chest and abdomen; thus, stimulation methods need to be improved.

Three methods should be considered to improve abdominal muscle stimulation. First, more bilateral stimulating sites would be expected to produce increased abdominal muscle contraction and exhaled volumes. Second, higher stimulating currents should produce stronger muscle contractions. For example, up to $100 \mathrm{~mA}$ is used with surface electrodes over abdominal muscles [10-14]. Third, current implantation sites in the midabdominal muscles may not be optimal, because this location is distal to the origin of lower thoracic nerves that innervate the abdominal muscles. Thus, stimulating along the lower thoracic ribs closer to the origin of intercostal nerves may increase abdominal muscle responses. However, achieving appropriate electrode locations will require a subcutaneous dorsolateral surgical approach along the caudal margins of the chest.

Placing the animal in a prone (face down) rather than supine position may facilitate abdominal responses to stimulation. The abdomen would probably expand downward in the prone position, allowing for larger volume changes during abdominal stimulations. In addition, the paradoxical expansion of the abdominal pneumobelt during abdominal muscle stimulation (Figure 3) in the supine position may not occur in the prone position.

Several methods should also be considered to improve upper-intercostal nerve and muscle stimulation. Including intercostal spaces two through five would be expected to have a positive effect. Interspaces six and seven should also be evaluated; however, these caudal interspaces are more likely to elicit contraction of abdominal (expiratory) muscles.

Clearly, a more secure and selective electrode in the upper thorax is needed to avoid unwanted contractions of the muscles overlying the ribs. Attaching the electrode to a bone screw at the caudal edge of the rib would prevent dislodgement. The current intramuscular electrode requires a large 16-gauge needle for implantation and cannot be inserted closer to the nerve. Thus, an electrode that could be implanted below the lower costal margin of the rib and closer to the nerve is needed. Another method for limiting the spread of the electric field is the use of bipolar electrodes [21]. However, more electrodes and leads are required for this method of stimulation.

\section{CONCLUSIONS}

We have developed techniques for stimulation of respiratory muscles by utilizing easily inserted Permaloc electrodes in the abdominal and upper-thorax muscles. Electrical stimulation delivered via the intramuscular electrodes elicited respiratory muscle contractions. Intercostal muscle stimulation was limited by coactivation of the serratus and latissimus muscles as well as by displacement of the electrodes. Coordinated stimulation of the diaphragm and upper-intercostal muscles followed by stimulation of the abdominal-wall muscles elicited tidal volumes that were larger than those elicited by diaphragm muscle stimulation alone.

\section{ACKNOWLEDGMENTS}

\section{Author Contributions:}

Study concept: J. S. Walter, R. D. Wurster, F. Laghi.

Study design: J. S. Walter, F. Laghi.

Study conduct: J. S. Walter, R. D. Wurster, Q. Zhu.

Acquisition of data: J. S. Walter, Q. Zhu.

Revisions of manuscript: J. S. Walter, R. D. Wurster, F. Laghi.

Financial Disclosures: The authors have declared that no competing interests exist. Synapse Biomedical, Inc's provision of electrodes, stimulators, and technical assistance is gratefully acknowledged. Synapse Biomedical, Inc, did not have any involvement in the study design; data collection, analysis, or interpretation; and writing or submission of this article.

Funding/Support: This material was based on work supported by the VA's Office of Research and Development, Rehabilitation Research and Development Service (grant B3008P). Synapse Biomedical, Inc, provided electrodes, stimulators, and technical assistance under a Material, Cooperative, Research and Development Agreement between the company and the VA.

Institutional Review: The Edward Hines, Jr. VA Hospital Institutional Animal Studies Committee approved these studies.

\section{REFERENCES}

1. Laghi F, Tobin MJ. Disorders of the respiratory muscles. Am J Respir Crit Care Med. 2003;168(1):10-48. [PMID: 12826594] DOI:10.1164/rccm.2206020

2. DiMarco AF, Onders RP, Ignagni A, Kowalski KE. Inspiratory muscle pacing in spinal cord injury: Case report and clinical commentary. J Spinal Cord Med. 2006;29(2):95-108. [PMID: 16739553]

3. DiMarco AF, Onders RP, Ignagni A, Kowalski KE, Mortimer JT. Phrenic nerve pacing via intramuscular diaphragm 
electrodes in tetraplegic subjects. Chest. 2005;127(2):671-78. [PMID: 15706014$]$

DOI:10.1378/chest.127.2.671

4. Onders RP, Elmo M, Khansarinia S, Bowman B, Yee J, Road J, Bass B, Dunkin B, Ingvarsson PE, Oddsdóttir M. Complete worldwide operative experience in laparoscopic diaphragm pacing: Results and differences in spinal cord injured patients and amyotrophic lateral sclerosis patients. Surg Endosc. 2009;23(7):1433-40. [PMID: 19067067] DOI:10.1007/s00464-008-0223-3

5. DiMarco AF, Romaniuk JR, Kowalski KE, Supinski GS. Efficacy of combined inspiratory intercostal and expiratory muscle pacing to maintain artificial ventilation. Am J Respir Crit Care Med. 1997;156(1):122-26. [PMID: 9230735]

6. DiMarco AF, Connors AF Jr, Kowalski KE. Gas exchange during separate diaphragm and intercostal muscle breathing. J Appl Physiol. 2004;96(6):2120-24. [PMID: 15133014] DOI:10.1152/japplphysiol.00628.2003

7. DiMarco AF, Altose MD, Cropp A, Durand D. Activation of the inspiratory intercostal muscles by electrical stimulation of the spinal cord. Am Rev Respir Dis. 1987;136(6): 1385-90. [PMID: 3688644$]$

8. Dunn RB, Walter JS, Walsh J. Diaphragm and accessory respiratory muscle stimulation using intramuscular electrodes. Arch Phys Med Rehabil. 1995;76(3):266-71.

[PMID: 7717821]

DOI:10.1016/S0003-9993(95)80614-8

9. Walter JS, Dunn RB, Wurster RD, Laghi F. Microstimulators and intramuscular hook electrodes for the stimulation of respiratory muscles. J Spinal Cord Med. 2007;30(4): 338-45. [PMID: 17853655]

10. Spivak E, Keren O, Niv D, Levental J, Steinberg F, Barak D, Chen B, Zupan A, Catz A. Electromyographic signalactivated functional electrical stimulation of abdominal muscles: The effect on pulmonary function in patients with tetraplegia. Spinal Cord. 2007;45(7):491-95.

[PMID: 17325697$]$

DOI:10.1038/sj.sc.3102039

11. Lee BB, Boswell-Ruys C, Butler JE, Gandevia SC. Surface functional electrical stimulation of the abdominal muscles to enhance cough and assist tracheostomy decannulation after high-level spinal cord injury. J Spinal Cord Med. 2008;31(1):78-82. [PMID: 18533416]

12. Lim J, Gorman RB, Saboisky JP, Gandevia SC, Butler JE. Optimal electrode placement for noninvasive electrical stimulation of human abdominal muscles. J Appl Physiol. 2007;102(4):1612-17. [PMID: 17185493]

DOI:10.1152/japplphysiol.00865.2006

13. Taylor PN, Tromans AM, Harris KR, Swain ID. Electrical stimulation of abdominal muscles for control of blood pressure and augmentation of cough in a C3/4 level tetraplegic.
Spinal Cord. 2002;40(1):34-36. [PMID: 11821968]

DOI:10.1038/sj.sc.3101250

14. Hascakova-Bartova R, Dinant JF, Parent A, Ventura M. Neuromuscular electrical stimulation of completely paralyzed abdominal muscles in spinal cord-injured patients: A pilot study. Spinal Cord. 2008;46(6):445-50.

[PMID: 18227852]

DOI:10.1038/sj.sc.3102166

15. DiMarco AF, Kowalski KE, Geertman RT, Hromyak DR. Spinal cord stimulation: A new method to produce an effective cough in patients with spinal cord injury. Am J Respir Crit Care Med. 2006;173(12):1386-89.

[PMID: 16543552]

DOI:10.1164/rccm.200601-097CR

16. DiMarco AF, Supinski GS, Petro JA, Takaoka Y. Evaluation of intercostal pacing to provide artificial ventilation in quadriplegics. Am J Respir Crit Care Med. 1994;150(4): 934-40. [PMID: 7921466]

17. DiMarco AF, Takaoka Y, Kowalski KE. Combined intercostal and diaphragm pacing to provide artificial ventilation in patients with tetraplegia. Arch Phys Med Rehabil. 2005;86(6):1200-1207. [PMID: 15954060]

DOI:10.1016/j.apmr.2004.11.027

18. DiMarco AF, Kowalski KE, Geertman RT, Hromyak DR, Frost FS, Creasey GH, Nemunaitis GA. Lower thoracic spinal cord stimulation to restore cough in patients with spinal cord injury: Results of a National Institutes of Health-sponsored clinical trial. Part II: Clinical outcomes. Arch Phys Med Rehabil. 2009;90(5):726-32.

[PMID: 19406290]

DOI:10.1016/j.apmr.2008.11.014

19. Lin VW, Deng X, Lee YS, Hsiao IN. Stimulation of the expiratory muscles using microstimulators. IEEE Trans Neur Sys Rehabil Eng. 2008;16(4):416-20.

[PMID: 18713679]

DOI:10.1109/TNSRE.2008.926705

20. Walter JS, Wurster RD, Zhu Q, Staunton C, Laghi F. Stimulating multiple respiratory muscles with intramuscular Permaloc electrodes. J Spinal Cord Medicine. 2010;33(2): 135-43. [PMID: 20486532]

21. Bresler L, Walter JS, Jahoda A, Wheeler JS, Turk T, Wurster RD. Effective methods of pelvic plexus nerve and bladder stimulation in anesthetized animal model. J Rehabil Res Dev. 2008;45(4):627-38. [PMID: 18712648]

DOI:10.1682/JRRD.2007.04.0058

Submitted for publication May 10, 2010. Accepted in revised form September 14, 2010.

This article and any supplementary material should be cited as follows:

Walter JS, Wurster RD, Zhu Q, Laghi F. Respiratory 
114

JRRD, Volume 48, Number 2, 2011

muscle pacing with chronically implanted intramuscular

Permaloc electrodes: A feasibility study. J Rehabil Res

Crossef nimBin

Dev. 2011;48(2):103-14.

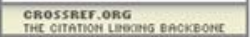

DOI:10.1682/JRRD.2010.05.0086 